\title{
THE LINGUISTIC SITUATION IN SUB-SAHARAN AFRICA IN THE POSTCOLONIAL PERIOD AND THE PROBLEMS OF LINGUISTIC DECOLONIZATION
}

\author{
V.M. Smokotin, G.I. Petrova, S.K. Gural
}

\begin{abstract}
The present research into the linguistic situation in the most multilingual region of the world, the Sub-Saharan Africa, pursues the goal to clear up the peculiarities of interrelations between the indigenous and European languages in this region as well as to provide a theoretical substantiation of the linguistic policies directed at ousting the European languages of the former metropoles from the most important spheres of life in the countries that achieved independence in the course of the $20^{\text {th }}$ century. The relevance of the research is determined, first of all, by the fact that there is a growing threat of a loss of linguistic and cultural heritage of the planet in the period of globalization. At the same time, the factors determining the loss of linguistic and cultural diversity of the world remain insufficiently researched. In accordance with the goal of the given work, the authors have sought answers to a number of questions connected with the functioning of multilingualism in the countries to the south of the Sahara. The most important of these questions are the following: 1) what are the main reasons for the failures of the policy of linguistic radicalism directed at ousting European languages from all main spheres of activities?; 2) how important is the role of European languages in the loss of linguistic and cultural diversity in the period of the acceleration of globalization processes?; 3) why is the concept of regarding languages as means of domination and suppression by the former colonial powers erroneous in the conditions of the countries of the Sub-Saharan Africa that became independent comparatively recently?

As the result of the present research it was found out that the radical linguistic policy of refusal from the languages of former metropoles by the governments of some of the African Sub-Saharan countries after achieving independence proved to be fallacious, since it was built without taking into account the instrumental function of languages. The main reasons for the domination of European languages in the countries of the region are explained by the historical development of the African countries in the colonial period, during which indigenous languages were developed exclusively for their use at the level of primary education. Another conclusion made in this article is that the approach to European languages with the status of state languages in the SubSaharan African countries as the chief source of threat of a loss of linguistic and cultural diversity is unjustified. The European languages as state languages in this region can present a danger to the indigenous languages and cultures only when they are used in the function of expressing ethnocultural identity, which is uncharacteristic of them.

Keywords: multilingualism and multiculturalism, linguistic and cultural diversity, lingua franca, linguistic radicalism, dominating languages, the instrumental function of language.
\end{abstract}




\section{Introduction}

The African continent attracts the researchers of the problems of multilingualism and multiculturalism as the most multilingual region of the world, whose linguistic and cultural diversity can be lost due to the acceleration of globalization processes [1:86-88]. However, the most interesting for researchers is the part of the African continent situated to the south of the Sahara, which is often referred to as 'Black Africa'. A prolonged isolation of that region from Europe has resulted in the fact that even after the period of European colonization, Sub-Saharan Africa stands out as the most multilingual and multicultural region of the world. According to the data of the Ethnologue, out of the total number of 2,100 languages in Africa, there are almost 2,000 living indigenous languages, the languages of the peoples of the tropical Africa to the south of the Sahara [2]. The largest in the world macrofamily of languages, Niger-Congoleze group, which includes Bantu languages, makes up 1,510 living languages spread over 39 countries of Tropical Africa.

The relevance of the present research follows from the need for a search for the ways of preserving and maintaining the linguistic and cultural heritage of the planet in the conditions of ever growing globalization. The goal of the research is to reveal the peculiarities of multilingualism in the countries of the Sub-Saharan Africa as well as the factors which determine the continuing domination there of the languages of the former metropoles as state languages, which, in the opinion of some critics, leads to the depreciation of the role of indigenous languages in the political, economic and cultural spheres of life of that region. To achieve this goal, the authors of the given work searched for answers to the following questions: 1) what are the main reasons for the failures of the policy of linguistic radicalism directed at ousting European languages from all main spheres of activities?; 2) how important is the role of European languages in the loss of linguistic and cultural diversity in the period of the acceleration of globalization processes?; 3) why is the concept of regarding languages as means of domination and suppression by the former colonial powers fallacious in the conditions of the former Sub-Saharan African colonies?

\section{Methodology}

The following methods adhering to the principle of systemic approach to the analysis of the investigated phenomena were used in the given research: historical method, which allows determining the place of the considered phenomena in the general sociocultural and linguistic situation of the world at different stages of development; linguistic method, which allows determining the influence of linguistic phenomena in the period of globaliza- 
tion and transformation of English into the language of worldwide communication; comparative method, which is necessary in determining the specifics of using languages as means of interlingual communication in various spheres of activities; analytical method, allowing to determine peculiarities of complex interaction of language and culture as well as the role of language functioning in a multilingual and multicultural society; systemic method, allowing to reveal interconnection of various linguistic and cultural phenomena and their complex influence on the interlingual and intercultural communication in the period of globalization.

The methodological basis of the present investigation rests on the works of scientists in the field of multilingualism [3, 4], in the field of research into the English language as means of international communication $[5,6]$, as well as on the works in the field of linguistic policies in the countries with colonial past [7-9], in research on linguistic and cultural diversity $[10,11]$, and in research into the instrumental function of languages [12-14].

\section{Research and discussion}

The problems of postcolonial development of Sub-Saharan countries are compounded by the difficulties caused by their continuing dependence on the former colonial powers not only in the field of national economies, but in the sphere of national education systems, particularly at the level of secondary schools and universities. The most complicated task there proved to be getting free from dependence of the new African nations on the European languages, which had penetrated deeply into all spheres of life of the former colonies. When planning their linguistic policies after acquiring independence, the Sub-Saharan African countries, with few exceptions, were forced not only to recognize the boarders, which were artificially imposed by the European colonizers in the process of occupation, division and colonization of the African territory, but to grant the European languages of the former metropoles the status of official languages [1: 98-108].

The preservation of the languages of the former colonial powers and granting them the status official languages de jure or de facto gives the African countries a number of advantages. All these countries maintain close economic ties both with the former metropoles, and with the other countries of Africa and the whole world sharing the same common language. Their official languages are also the official languages of all large international organizations, including the United Nations and UNESCO. All African countries are members of communities united by a common language and common historical development as former colonies of one of the European powers. The largest community of such type is the Commonwealth of Nations, representing an intergovernmental organization of fifty three independent member-nations, most of which were members of the British Em- 
pire. The head of the Commonwealth, Queen of the United Kingdom, is also the Queen of six member-nations of the Commonwealth. Formally, the Commonwealth of Nations was established yet in 1931 by the Statute of Westminster. After the former colonies and dominions acquired independence, the cooperation between the members of the Commonwealth developed on the basis of equality and mutual assistance in the spheres of culture, sports, economy and education. To this aim, within the framework of the Commonwealth, function intergovernmental organizations, specializing in cooperation and mutual assistance in a certain sphere. The Commonwealth Business Council, set up in 1996, is aimed at using the worldwide network of the Commonwealth in order to promote the development of national economies and the world trade. The Commonwealth of Learning assists developing countries in the organization of a free access to high quality education at all levels by means of providing the necessary knowledge and skills as well as resources and technologies. Under the aegis of the Commonwealth there are more than 100 non-governmental organizations, including the Association of the Commonwealth Universities, the Association of the Commonwealth Lawyers, etc.

Cooperation of the Bitish Commonwealth countries turned out to be so effective that a number of countries that were never a part of the British Empire, including the former French colonies Algeria, Madagascar and Rwanda, have applied for joining this organization [15].

There are also associations of francophone and lusophone countries, whose member-nations enjoy a number of advantages as developing countries, particularly in the spheres of education and culture. The international organization of the francophone countries (Organisation internationale de la Francophonie) includes 56 member-nations, 3 associative members and 14 observers. The Francophonie was established in 1970 under the motto of 'égalité, complémentarité, solidarité' as an organization promoting the French language and culture, and in the course of time grew over into a large organization cooperating in the fields of culture, science, national economies, legislature and peace [16].

The Association of the Countries of the Portugese language (Comunidade dos Países de Língua Portuguesa, CPLP) was set up comparatively recently, in 1996, and includes eight member nations, five of which are situated to the south of the Sahara. The CPLP has already demonstrated its effectiveness when it helped two African countries (São Tomé and Príncipe, and Guinea-Bissau) to settle problems of political and economic instability in connection with coup d'états. The CPLP's initiatives to assist member countries include programs for developing business and public governance, campaigns for struggle against malaria and HIV / AIDS, diseases which cause great harm to African national economies. Particularly close cooperation takes place in the spheres of culture and education [17]. 
After the collapse of the colonial system, the problems of adaptation of formal education to national realities and creating conditions for a gradual replacement of the European languages as mediums of instruction at all levels were included as priority issues into the political agendas of many countries of this region. The lessons of experimenting with linguistic policies, as Nigerian researcher in the field of education, Pai Obanya, writes, have clearly demonstrated the difficulties of carrying out radical reforms connected with transfer to new languages of instruction. The education reforms in a number of Sub-Saharan African countries have passed through four stages, during which the attitudes to education in indigenous languages were changing from positive to negative:

- a period of explanatory work, during which measures were undertaken for disseminating among the people the idea about a need for developing indigenous African languages for the purposes of education;

- a period during which a practical work was carried out in creating in francophone countries writing systems and school textbooks for local languages, and in anglophone countries a campaign was underway for writing systems reforms and encouraging literary creation in indigenous languages;

- a period of broad initiatives in linguistic policies in such African countries as Tanzania, Ethiopia, Somalia, Madagascar and Guinea to select national languages for their comprehensive development to be used in basic education and teaching literacy;

- a period of slowing down and suspending experiments in linguistic policies, when African leaders started to refuse from a wide use of indigenous languages in education, particularly at higher levels than primary education [18].

However, not all Sub-Saharan countries in Africa, as part of decolonization, following the declaration of independence, pursued the goal of replacing the European languages with one or a group of African languages in all spheres of life of their countries, starting from the state governance. Radicalism in the field of linguistic policies and "linguistic decolonization" were characteristic for those countries whose leaders during their national liberation struggle developed the idea of the postcolonial development of their countries along "the path of African Socialism" and full decolonization, including the refusal from the use of European languages as the official languages of the country. Thus, Julius Nyerere, the president of Tanzania in the period of 1964-1985, promoted, within the framework of the conception of "Education for self-reliance", a wide use of Swahili and ousting of the English language from school education system in Tanzania [19]. The other follower of the ideas of African socialism and complete decolonization, Ahmed Sekou Toure, the president of Guinea from 1958 to 1984, immediately following the declaration of independence got down to the decolonization of education and a gradual replacement of the French language with African 
languages. With this purpose in mind, six indigenous languages were selected, and a work got underway for their development and creating educational materials for a transfer to instruction in indigenous languages at all levels of education. Radicalism in the field of linguistic policies, however, did not lead to what was expected. In Guinea, the rupture of political and economic relations with France told negatively on the postcolonial development of the country "along the path of socialism and independence". After a change in the linguistics policies of the government, the French language resumed its positions in school education, and the indigenous languages changed their status from the mediums of instruction to subjects within the school curriculum.

In spite of the domination of European languages in the countries of Sub-Saharan Africa, there are certain differences in linguistic policies in the field of education between, on the one hand, the Anglophone and, on the other hand, the francophone and lusophone nations there. Thus, most of the English speaking countries of Black Africa aim at achieving literacy in native languages, and school teaching in the first one to two years of primary school is conducted in native languages, while English is taught as a subject. At the following stages of teaching, African languages are taught as subjects in the school curricula, and English is used as the medium of instruction. In francophone and lusophone countries of Sub-Saharan Africa, the native language is taught as a subject even in primary school, and the goal of achieving literacy in African languages is not set. In those African countries where non-European languages have the status of official ones (in Tanzania, Madagascar, Burundi, Rwanda, Somalia and Ethiopia), instruction in native languages takes place during the whole period of basic education. At the levels of secondary and higher education, European languages take over as mediums of instruction [20].

Due to the growth in the late 1990s of the popularity of multilingualism and multiculturalism in the developed countries of the West, particularly in Europe, calls for a revision of the linguistic policies in the Sub-Saharan countries became frequent in Black Africa's political and in intellectual circles. Ali Mazrui, Kenyan academic professor and political writer, in his research into the use of European languages as state languages in Africa, stated that the belief of certain African leaders in the superiority of the Western model of development, including the use of European languages, as contributing to more successful sociopolitical development of the former colonies, is erroneous. He claimed that "linguistic pluralism is not necessarily a dividing force that weakens the bonds of statehood and national existence, but, on the contrary, can be a powerful source of new humaneness in the world of remarkable diversity" [7].

Tanzanian researcher in the field of education, Walter Bgoya, calls English, the most widely used language in Africa, "an export commodity and the language of colonial conquest and domination", and expresses his opin- 
ion that "artificial imposing of an alien language leads not only to a failure in achieving perfection in this language, but also to losing proficiency in one's native language" [8].

If the calls of the proponents of complete linguistic and cultural decolonization appear to be rather unpractical in the conditions of Africa's extraordinary diversity and the difficulties of selecting certain African languages and their development with the aim to use them at all levels of education, in national economies, in science research and as languages of interethnic communication, the idea of granting the most spoken African language, Swahili, the status of an official language, appears to be quite acceptable. Swahili emerged on the Eastern coast of Africa as the language of common communication of Arab traders mounting regular expeditions with caravans of camels along the Eastern coast long before the start of European colonization. It contains more than 35 percent of words of Arabic origin, and is the only African language performing the function of a lingua franca on the African continent. Swahili is a native language for 5-10 million people, and is used as a second language in many countries of Eastern Africa, where it is spoken by about 50 million people. Swahili has the status of an official language in Kenia, Tanzania and Uganda. Besides, it is the only African language which has been included into the list of official languages of the African Union, the largest intergovernmental organization in Africa [9].

Swahili's development into a recognized African language of interethnic communication that has its own system of writing and its standard form, however, was the result of a purposeful policy of colonial powers. Great Britain and Germany, which seized huge territories in Eastern Africa, pursued the policy of selecting the most widespread local languages to be used in primary education and at the lowest levels of colonial governance. After the First World War, Swahili was used by the British colonial administrations in Uganda, Tanganyika, Zanzibar and Kenya, and in the process of its use, its vocabulary and grammar were standardized. Swahili existed in the form of a multitude of dialects, which led to difficulties in communication. The colonial authorities took measures in standardizing Swahili and reforming its writing, as the result of which the Arabic script was replaced with Latin alphabet. The final standardization of Swahili took place in June 1928 at an interterritorial conference in Mombasa (Kenya), at which the Zanzibar dialect of Swahili, Kiunguja, was selected as its standard form [21]. Since then, Zanzibar Swahili is studied all over the world as Swahili's standard form, even though there are certain differences between the standards and the spoken form of Swahili in Zanzibar.

The fact that Swahili is the product of colonial politics, and that it was developed for limited purposes, which did not include its use at the highest level of government, in university education and science research, raises the question of expedience of the efforts to advance this language into functions 
uncharacteristic for it without a long period of developing its vocabulary and gradual induction into new functional use. Some African authors in general express doubts about the authenticity of African languages, since all Afican languages studied at school are the result of activities of colonial authorities to create languages of communication of bilingual colonial administration with the local population. Thus, a group of African authors from the University of Pennsylvania (the USA) has advanced a conception, according to which during the colonial period Europeans appropriated African languages as a prelude to imposing on African peoples the European versions of African languages under the guise of promoting the development of indigenous languages [22].

Declaring one or a few African languages as official alongside the European languages in the former colonies of imperialist powers does not mean the end to the dependence of the African countries on the languages of former metropoles. European languages continue to occupy a dominating position in school and university education, in national economies, in media and political life. Even in Ethiopia, Eritrea and Somalia, the countries which either avoided colonial rule, or experienced relatively lower impact of colonial governance, and which continue to use as official the indigenous African languages, the use of their official languages in the system of education is often limited to basic education level. Thus, Ethiopia, which was not a part of the colonial partition of Africa, uses the Amharic language, the most widespread language in the country, as the language of the federal government. However, even at the level of primary school in the national education system, instead of Amharic there may be used other local languages. At the level of secondary and university education, the medium of instruction is English [23]. In Somalia, the official languages are Somali and Arabic, which are also widely used in school education. The English language, however, continues to dominate in higher education, particularly in majors of science engineering profile.

The linguistic radicalism of the leaders of some of the Sub-Saharan African countries, which led to the fallacious linguistics policies of rejection of the European languages without a prolonged transitional period of developing indigenous languages to be used in the most important spheres of activity, manifests the complexity and versatility of language as the most important means of human communication, storage and transfer of information, controlling human behavior and cognition of the surrounding world [24: 151-160]. The positions of the politicians supporting the ideas of linguistic radicalism found most salient exposition in Robert Phillipson's work "Linguistic Imperialism" [25]. Phillipson condemned the use of European languages in the countries which became independent following the collapse of the colonial system as manifestation of neocolonialism. On the example of the "English linguistic imperialism" he claimed that the domination of the 
English language in the world is linguistic imperialism, which, in its turn, is a form of linguicism, that is discrimination on the basis of "knowing-not knowing" of the dominant language [25: 50].

The approach to a language from the point of view of power relations, that is, considering the language as a weapon of colonial domination and a means of ensuring cultural hegemony, appears to be as unreasonable as a refusal from using a tool or device, justifying it by pointing out that they were designed or manufactured by people who do not share our world outlook. Interdisciplinary studies of language in the second half of the $20^{\text {th }}$ century allowed researchers to reveal different approaches to the understanding of language as a phenomenon and to explain the failures of linguistic policies directed at refusal from the use of some languages as remnants of the colonial past. Lev Vygotsky was one of the first who spoke about the instrumental function of languages $[12,13]$. He pointed out that "the language, particularly the language of science, is the tool of thought and an instrument of analysis" [12: 356]. The idea about the instrumental function of the language was further developed in the works of a number of researchers, who regarded the language as a "tool for interacting minds". In 1997, Andy Clark in the book "Being There" substantiated the concept of the language as a tool of human activities, which allows not only solving problems, but achieving such goals which could not be reached without its use [26]. The properties of the language as an instrument of cognition were also revealed by a group of researchers in the field of linguistics and interlingual and intercultural communication from Aarhus University (Denmark), who in the research published in 2010 described the ways of using the language as an effective tool for interacting minds, which allows performing joint actions [14].

\section{Conclusion}

Thus, in spite of differences in the history of the evolution of linguistic policies in the countries of Sub-Saharan Africa that were determined both by peculiarities of colonial policies in the field of school education, and by the degree of radicalism of the leaders in the struggle for independence, the European languages of former metropoles continue to dominate as state languages in most countries of the region. Even in the countries where indigenous languages have the status of official languages alongside with the European ones, European languages continue to dominate in the systems of education above the basic level in schools and in higher education as well as in economic, business and science and research activities.

The causes for the domination of European languages in the countries of the region have their roots in the linguistic policies of the colonial administrations: indigenous languages were used exclusively at the level of primary education. The linguistic radicalism of some of the African leaders, whose 
linguistic policies were aimed at replacing European languages with indigenous African languages at all levels of education and in the work of governmental organizations, did not lead to the desired results.

The theory of linguistic imperialism of Robert Phillipson, according to which using languages of the former metropoles as official languages perpetuates colonial dependence of the third world countries, is not sufficiently substantiated, since it does not take into account the instrumental functions of languages. The use of European languages as the languages of government and education in the former colonial possessions presents no threat to linguistic and cultural diversity due to separation of functions performed by languages in different spheres of those countries. Negative consequences for linguistic and cultural heritage take place only in cases when European languages in the status of official languages take over the functions of expressing ethnocultural identity.

\section{Information about the authors:}

Smokotin V.M. - D.Sc. (Philosophy and Culture), Professor, Faculty of Foreign Languages, Tomsk State University (Tomsk, Russia). E-mail: vladimirsmokotin@yandex.ru

Petrova G.I. - D.Sc. (Philosophy), Professor, Faculty of Philosophy, Tomsk State University (Tomsk, Russia). E-mail: seminar2008@mail.ru

Gural S.K. - D.Sc. (Education), Professor, Faculty of Foreign Languages, Tomsk State University (Tomsk, Russia).E-mail: gural.svetlana@mail.ru

\section{References}

1. Smokotin, V.M.: Multilingualism and the Problems of Overcoming Interlingual and Intercultural Barriers in the Modern World. Tomsк: Tomsk State University (2010)

2. Statistical Summaries by area // Lewis, M. Paul (Ed.). The Ethnologue, $16^{\text {th }}$ Edition, Dallas, Texas: SIL International (2009)

3. Bialystok, E. et al.: Bilingualism, Consequences for Mind and Brain // Trends Cogn. Sci., 16 (4), 240-250 (2012)

4. Grosjean, F.: Bilingual: Life and Reality. Cambridge, Mass.: Harvard University Press (2010)

5. Crystal, D.: English as a Global Language. Cambridge University Press (2000)

6. Graddol, D.: English Next: Why Global English May Mean the End of English as a Foreign Language in the $21^{\text {st }}$ Century. London: The British Council (2006)

7. Mazrui, A.A., Mazrui A.M.: The Power of Babel: Language and Governance in the African Experience. London: James Currey, Limited (1998)

8. Bgoya, W. The Effect of Globalization in Africa and the Choice in Language Publishing // International Review of Education, Vol. 47 (3-4), 283-292 (2001)

9. Lutz, M.: Swahili // Encyclopedia of Language and Linguistics, $2^{\text {nd }}$ ed., New York: Elsevier (2006)

10. Greenberg, J.H.: The Measurement of Linguistic Diversity // Language (Journal of Linguistic Society of America), Vol. 8 (2) (2003)

11. Nettle, D., Romaine S.: Vanishing Voices: The Extinction of the World's Languages. Oxford: Oxford University Press (2000)

12. Vygotsky, L.S.: The historical meaning of the psychological crisis. Collected works in six volumes. M.: Pedagogika, 1982-1988. Vol. 1. 291-459

13. Vygotsky, L.S.: Cognition and Speech. $5^{\text {th }}$ edition. M.: Labirint (1999) 
14. Tylén K., Weed E., Wallentin M., Roepstorff A., Frith, Ch.: Language as a Tool for Interacting Minds // Mind \& Language. Vol. 25 (1), 3-29 (2010)

15. Membership of the Commonwealth: Report of the Committee on Commonwealth Membership // Commonwealth of Nations, London: Commonwealth Secretariat (2007)

16. Francophonie // The Canadian Encyclopedia. Ontario: Historica Foundation of Canada (2008)

17. Africanidade // CPLP. http: // www.cplp.org

18. Obanya, P.: Language Education in Africa: Lessons for and from Nigeria. // Fafunwa Foundation Internet Journal of Education. Vol. 1, Editorial (1998)

19. Kassan, Y.: "Julius Nyerere". In: Z. Morsy (ed.). Thinkers in Education. Paris: UNESCO Publishing (1995)

20. Obanya, P.: Patterns of Educational Reform in Africa // Prospects, Vol. 28 (4) (1998)

21. Whiteley, W.: Swahili: the rise of a national language. London: Methuen Series: Studies in African History (1969)

22. Makoni, S.B., Dube, B., Mashiri, P.: Zimbabwe Colonial and Post-Colonial Language Policy and Planning Practices // Current Issues in Language Planning, Vol. 7 (4), $377-$ 414 (2006)

23. Damtew, T., Altbach, P.G.: African Higher Education: An International Reference Handbook. Indianapolis: Indiana University Press, 316-325 (2003)

24. Smokotin, V.M.: The language of worldwide communication and the ethnocultural identity: comlementarity in the conditions of globalization. Philosophy Doc. diss. Tomsk State University (2012)

25. Philipson, R.: Linguistic Imperialism. Oxford: Oxford University Press (1992)

26. Clark, A.: Being There (Putting Brain, Body and World Together Again). Cambridge, MA: The MIT Press (1997) 